Supplement of The Cryosphere, 12, 2267-2285, 2018

https://doi.org/10.5194/tc-12-2267-2018-supplement

(C) Author(s) 2018. This work is distributed under

the Creative Commons Attribution 4.0 License.

(c) (1)

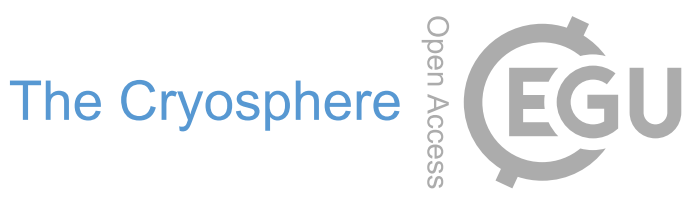

Supplement of

\title{
Melting and fragmentation laws from the evolution of two large Southern Ocean icebergs estimated from satellite data
}

Nicolas Bouhier et al.

Correspondence to: Jean Tournadre (jean.tournadre@ifremer.fr)

The copyright of individual parts of the supplement might differ from the CC BY 4.0 License. 
Abstract. The Supplementary information provides the full resolution analysis of the MODIS images for the detection of the pieces calved from C19a and B17a.

The SI presents the four full resolution MODIS used to analyse the size distribution of the fragments calved from B17a and C19a.

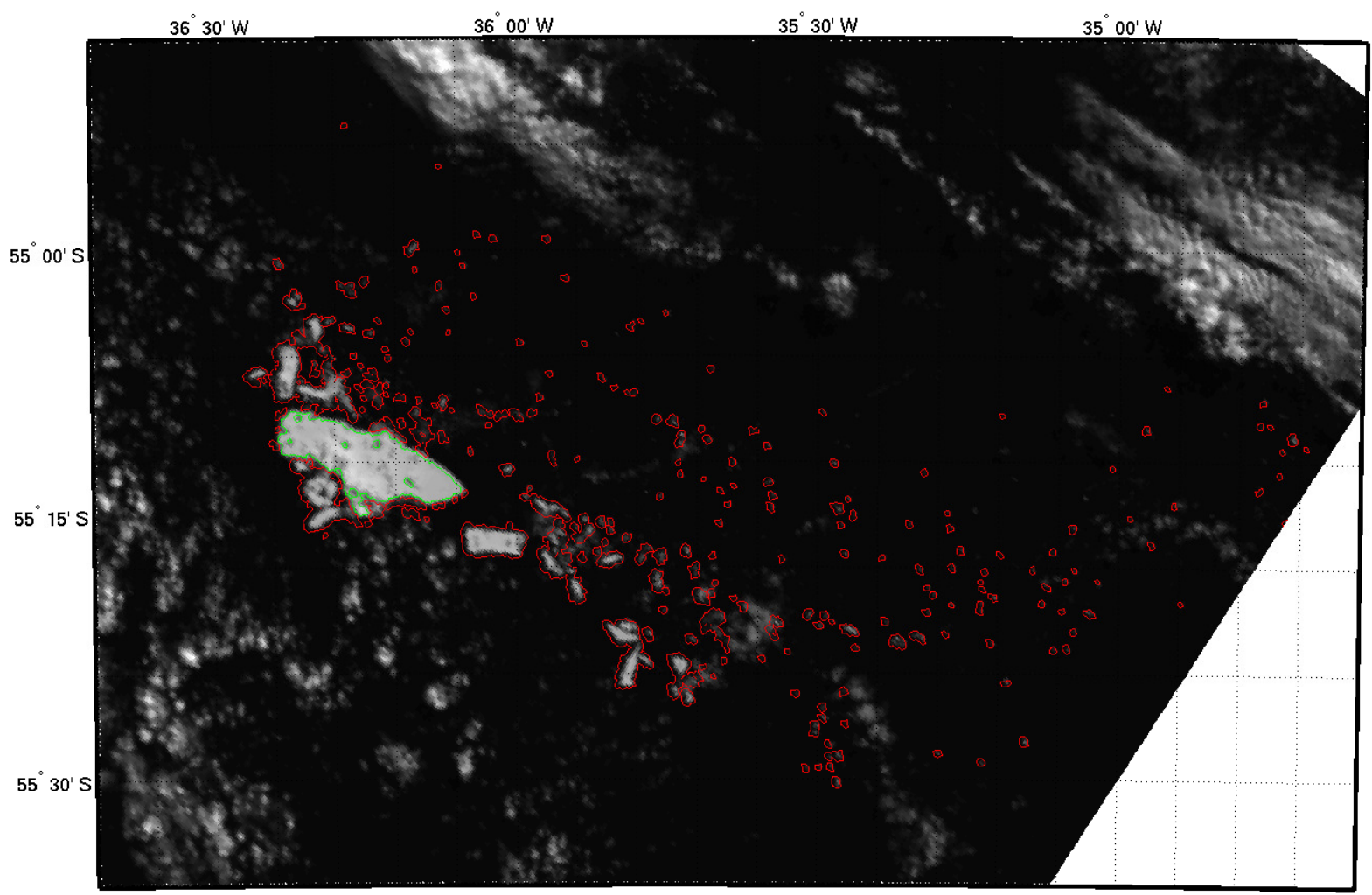

Figure S1. MODIS image of B17a on 03/21/2015 18:55UT. The green line delineates B17a and the red ones the smaller icebergs. 


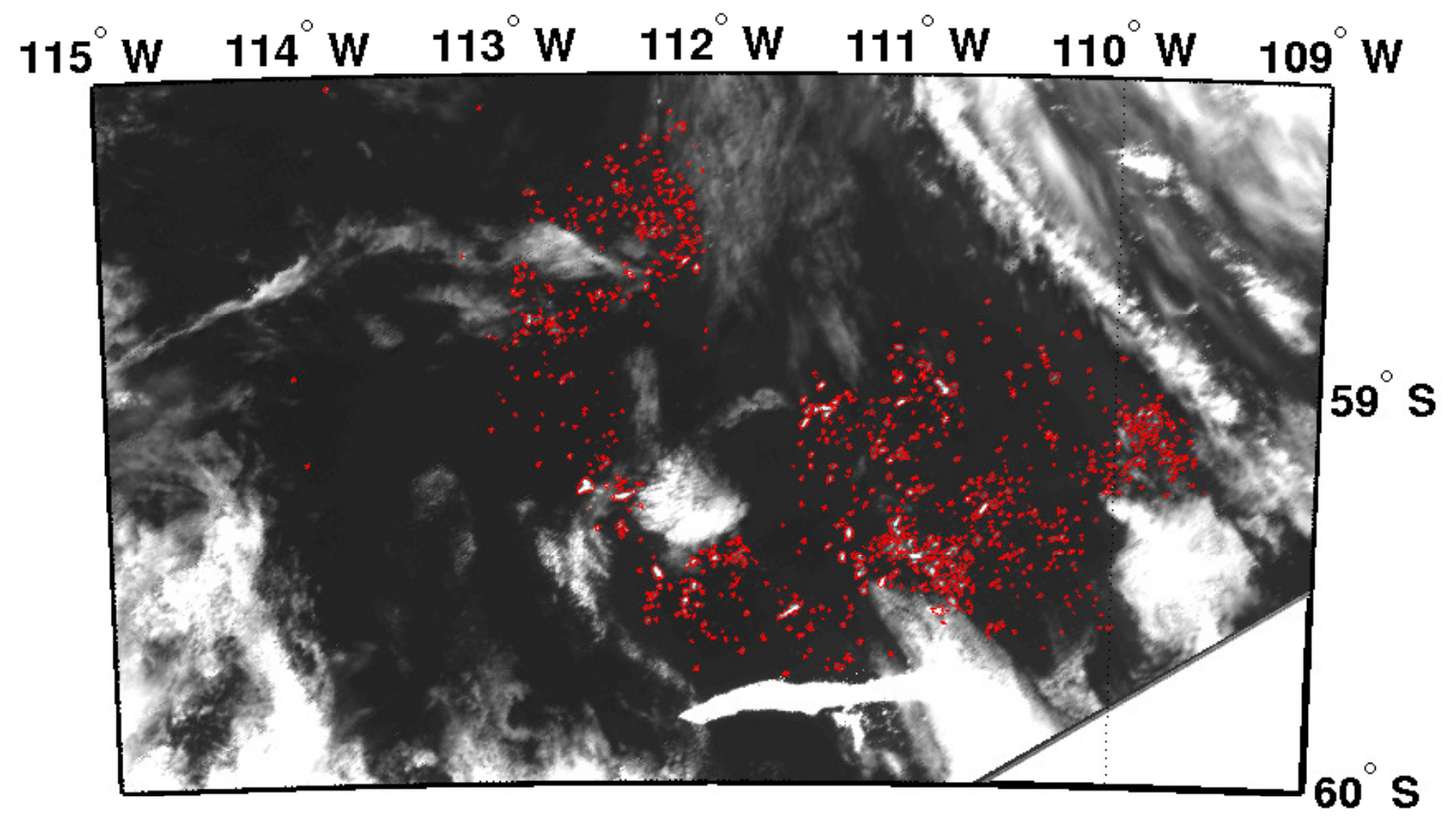

Figure S2. MODIS image of C19a on 02/05/2009 23:05UT. The red lines delineate the smaller icebergs. 


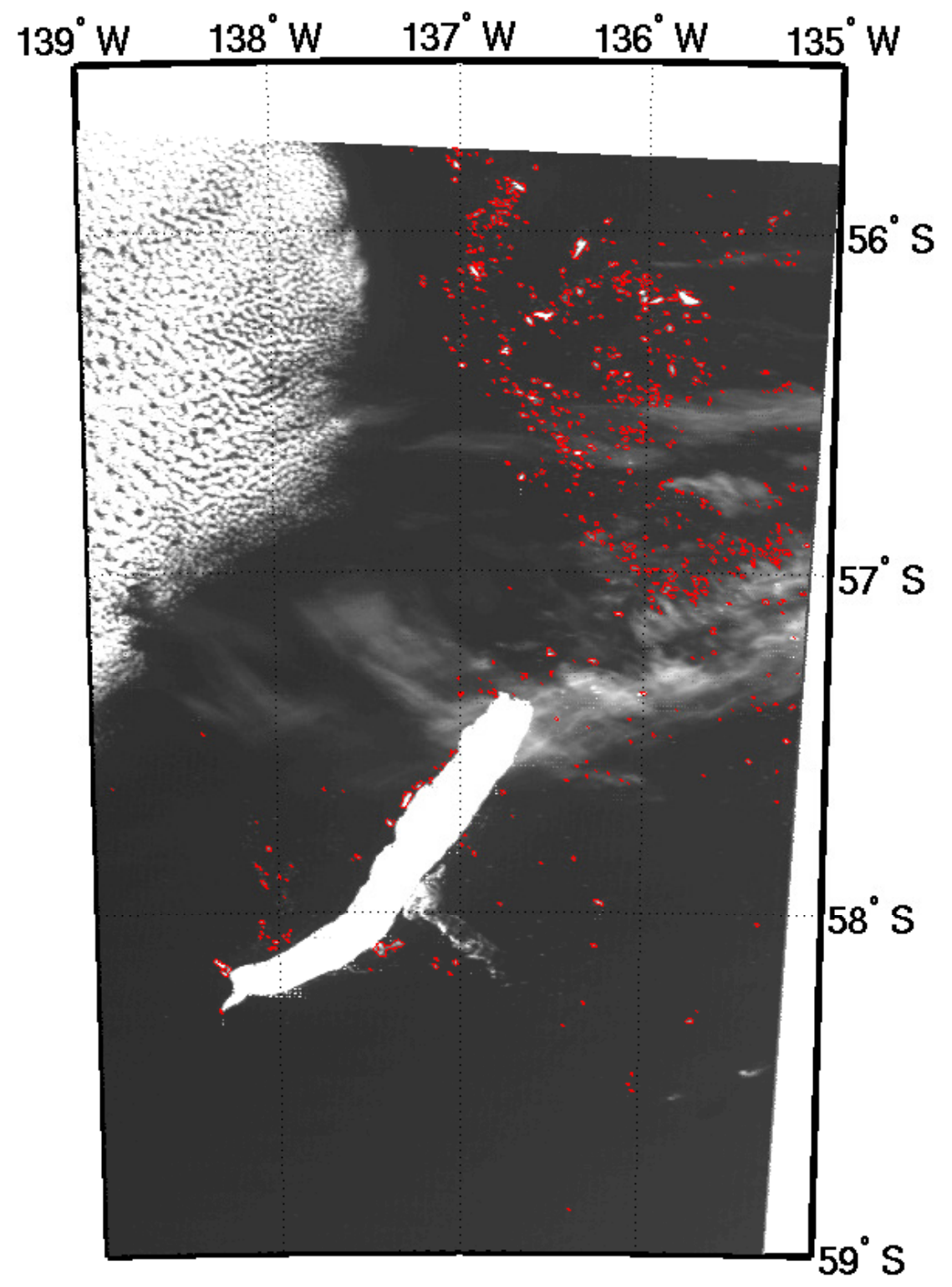

Figure S3. MODIS image of C19a on 08/15/2008 18:45UT. The red lines delineate the smaller icebergs. 


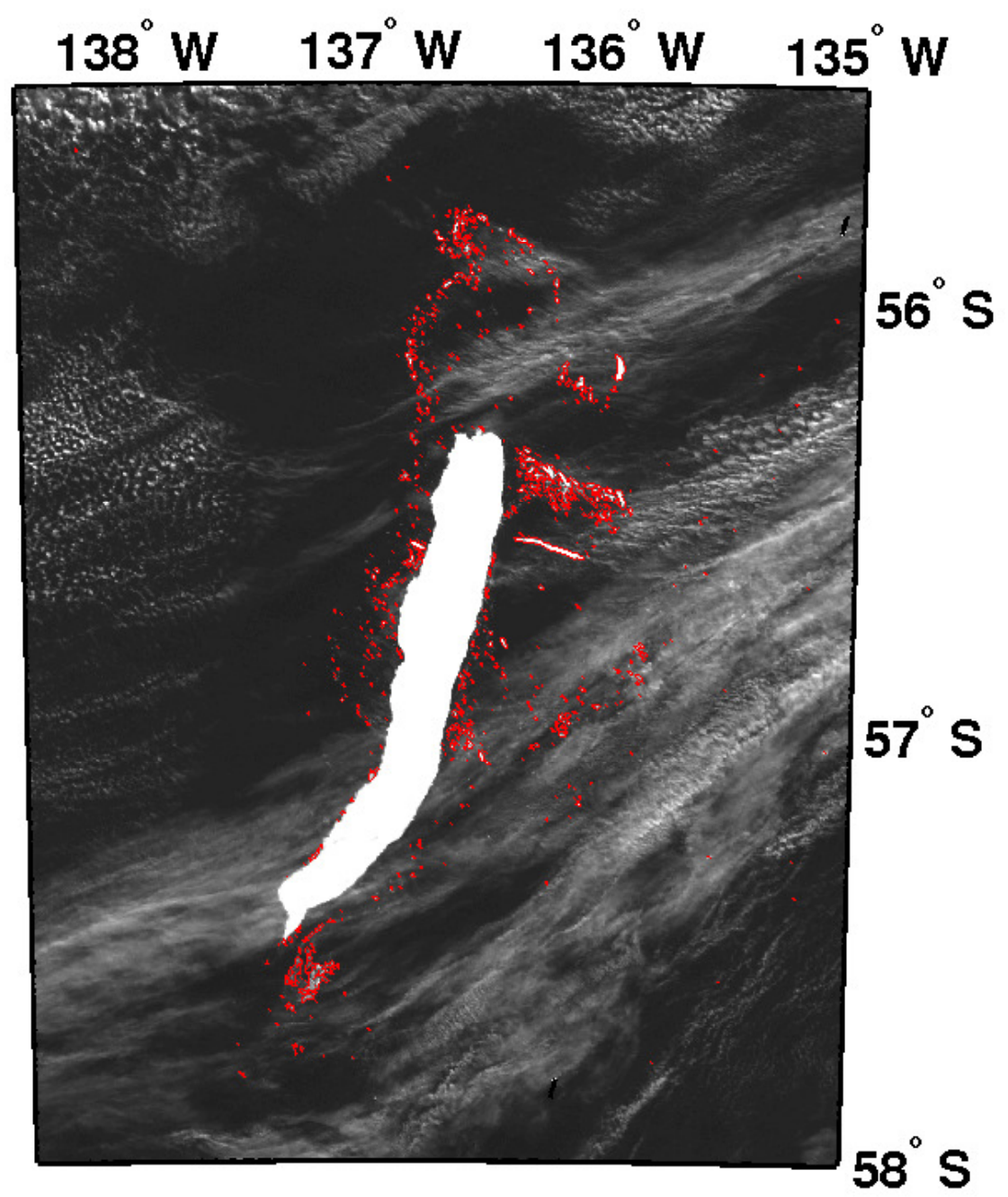

Figure S4. MODIS image of C19a on 08/21/2008 19:20UT. The red lines delineate the smaller icebergs. 